\title{
298 )
}

XXI. On the Determination of the Species, in Mineralogy, according to the Principles of Professor MoHs, By William Haidinger, Esq. F. R.S. Edin.

( Read November 15. 1824.)

A Justiy celebrated Naturalist* was of opinion, " that every " distribution of mineral bodies, which is instituted before the " determination of the species, must be mere confusion; while, " after having established it, according to fixed principles, no " kind of distribution can be absolutely faulty." The distribution itself varies, along with the different principles of classification, introduced for the purpose of obtaining a systematic arrangement, conformable to the views of Natural History, of Chemistry, or of other sciences; but the Species remains that unique and unalterable point to which every system, and in fact every inquiry, must be referred, if we wish to avail ourselves of the prerogatives of the human mind, and preserve our information in a scientific form.

The correct determination of the species is equally important to every branch of our knowledge, in regard to the objects of nature; since there does not exist another general idea applicable to the same extent, or equally fertile in producing order and stability, within the daily increasing mass of observations. It is

* Dolomieu, Sur la Philosophie Minéralogique, p. 113. Avant d'avoir préalablement fondé l'espèce, toute distribution n'est que confusion; après Tavoir établie sur des principes fixes, aucune distribution ne peut être, jusqu' à un certain point, vicieuse, parce qu'elle a toujours un fanal qui l'éclaire, un point de rappel d'où partent toutes les relations, et auquel toutes doivent concourir. 
Mineralogy, according to the Principles of Professor MoHs. 299

the foundation of scientific Mineralogy, and it must, on that account, be reduced to constant and philosophical principles, and not be left at the mercy of chance and empiricism.

If we consider the progress of mineralogical systems from the first attempts of LinNaus to the present day, it appears that, while the general scientific form of the systems was insensibly lost,-while essential degrees of classification were abandoned,-while even the characteristic marks between substances resembling each other were deemed superfluous * ; the determination of the species continued gradually to approach nearer to perfection. The system of Linneus, with its ternary distribution, containing three classes, each of which comprises three orders, and the system of WALleniUs, with its quaternary distribution, each of his four classes comprehending four orders, gave way to the systems of Cronstent and Werner, in which the characteristic differences, and the order, as a unity of classification, disappeared, and to the system of $\mathrm{H}_{\mathrm{AüY}}$, in which distinctive characters are introduced, not for discriminating a newly observed individual from all the rest, but for producing a contrast between it and one or a few others, mentioned by name, and which, moreover, at least in one, and the most numerous of its classes, contains neither orders nor genera.

However valuable the labours of WerNer may have been in clearing the mineral system of compound rocks formerly held, along with the simple minerals, to be proper objects of mineralogy, yet it is particularly to the accurate investigations of the forms by HAÜY, resting, in part, upon RoME' DE L'IsLE's observations, that we are indebted for a more correct determination of the species contained in his system. This greater degree of correct-

* Linneus, when speaking of the system and principles of Cronstedt, says, "Definitiones characteristicas inutiles judicat: sufficere nosse."-Syst. Nat. 


\section{$300 \mathrm{M}_{\mathrm{R}} \mathrm{H}_{\text {aldinger }}$ on the Determination of the Species in}

ness has been rather the consequence of a more intimate acquaintance with nature, than the result of applying philosophical principles to observation. The application of geometry in the consideration of forms, imparted precision to a property which had hitherto been as vague and uncertain as others The striking contrasts offered by the forms of different species being once recognised, it became almost impossible for $\mathrm{H}_{A} \ddot{\mathrm{C} Y}$, and subsequent crystallographers, to fall into the same errors which render the systems of an earlier period useless. The crystallographic method of WERNER was far from affording precision and security, in its determinations ; and his species, there-

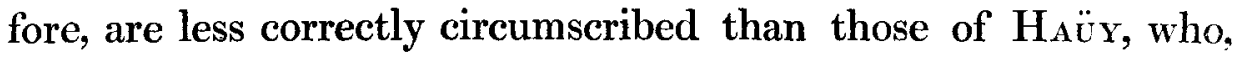
notwithstanding the great superiority of geometrical evidence to that of mere inspection, considered the introduction of a chemical principle into the determination of the species as unavoidable. Although chemistry has always exercised a great influence upon the methods received in mineralogy, it cannot be said that this was more particularly the case in respect to the establishment of the idea of the species, when it even required the sagaeity of RoME' DE L'IsLE to demonstrate that there really were such things as true species in the mineral kingdom, which till then was denied by the chemists of the day. The Wernerian System demonstrates, in every one of its departments, that it has in fact no principle upon which it might be said solely to depend; and the characteristic ingredient itself may be ambiguously interpreted. This want of unity in the principle of the Wernerian system, has perhaps nowhere been more plainly expressed than in the first edition of Professor J Jueson's System of Mineralogy, where we find the following passage: "The Wer" nerian oryctognostic system is founded solely on the natural "alliances and differences observable among minerals. But on " what do these depend? Werner answers, on the quality, 
Mineralogy, according to the Principles of Professor MoHs. 301

"quantity, and mode of combination of the constituent parts." This is in fact tacitly supposing the results of mineralogy and chemistry already to have been brought to a degree of coincidence, which, though it may be rightly anticipated, has yet not been established, even by the recent most rapid progress of the two sciences. In this way the determination of the species of WERNER, was almost entirely left to a certain tact which admits of no definition, and must be more admired in the correct results occasionally obtained, than praised for the certainty with which the method could be pursued.

The definition of the species, as given by $\mathrm{H}_{\mathrm{AU}} \mathrm{Y}$, that it comprises bodies having similar integral molecules, and being composed of the same elements, in the same proportion *, consists of two heterogeneous parts, the first of which, taken alone, is insufficient, though appertaining to the science, while the second is altogether foreign to mineralogy.

Natural Philosophy has been defined as " the science that " unfolds those general principles which connect the events of " the material world †." As a branch of natural philosophy, the science of Chemistry regards the events produced by the action of bodies upon each other, in which the changes produced are permanent, and, therefore, like the whole of natural philosophy, it investigates phenomena in reference to their causes.

It is necessary to know what things those are, which act upon one another; and definitions must therefore precede, before it is possible to enter into the details of these sciences themselves. One word may very often suffice for the definition of one object, but if there be a great many, some of them, too, possessing very similar properties, a degree of order must be introduced, even in the enumeration of the above-mentioned definitions.

* Traité, t. i. p. 162.

+ Lesuie, Elements of Natural Philosophy, p. 1. 
Confining ourselves, in the present place, entirely to the productions of Nature, there are in fact a great many bodies, which more or less resemble each other. The problem to be resolved here, as a first process to the introduction of other sciences, will be to discriminate those which resemble each other most. This discrimination is the object of Natural History ; a science, therefore, which proceeds upon the principle of similarity.

Hence, it appears, that Chemistry and Mineralogy most materially differ in regard to the point of view from which they consider the productions of inorganic nature.

Mineralogy treats of those properties which minerals exhibit in their natural state ; it collects the individuals within the ideas of species, genera, \&c., and, teaches us how to distinguish them from one another. Chemistry refers to the substances of which the natural-historical species consist; it treats of the properties of inorganic matter, manifested during the process of its forming new combinations, and teaches us to recognise these substances, not only in their pure state, but in all their various mixtures and combinations ; and it enables us, by the comparison of its results with the species previously determined, to form an opinion of the chemical constitution of the latter.

The establishment of what may be with propriety considered as a Species in Natural History, according to the pure principles of that science, is its most important object, because its whole scientific progress depends upon this idea. Mineralogists have hitherto, almost uniformly, considered it as impracticable to attempt the construction of systems, or the definition of the species, without the assistance of chemistry : nay, professed mineralogists have not hesitated to allow to the identity of chemical substance, the first and most important place among the considerations upon which they ground their species; and, owing to this preponderancé, we see Arragonite and Calcareous-spar, and the hexahedral and prismatic Iron-pyrites, in recently published 
Mineralogy, according to the Principles of Professor MoHs. 303

systems, degraded to subspecies or varieties of carbonate of lime, and sulphuret of iron *.

These systems shew, that, in reality, they are not intended for mineralogical purposes, but for exhibiting the present state of our information respecting the chemical constitution of the mineralogical species. They endeavour to exclude, in the formation of the species, the influence of those properties which the productions of inorganic nature possess in their natural state; but, it is evident, from the want of consistency in their different parts, that they cannot arrive at their purpose, unless they admit, as their leading point of comparison, the species, determined without the slightest influence of chemical properties or considerations.

Professor Mors has succeeded in producing a definition of this idea, founded entirely upon the comparison of those properties which may be observed while the minerals continue in their natural state; and it is the object of the present paper to point out the course, and to develope the principles, conformable to which he has arrived at this important result.

There can be no doubt, that, in Mineralogy, as well as in Zoology and Botany, the species should comprehend the assemblage of those individuals which are most closely allied to each other. The exactness of the definition will therefore depend upon the signification we attach to individuals, and to the degree of alliance necessary for joining them within one and the same species.

Natural History requires that an individual be a single Body, and, as such, by itself, fit to be an object of natural-historical consideration. It implies unity of form, and does not presuppose the existence of, or connection with, another individual.

* Beudant, Traité élémentaire de Minéralogie, p. 406. 425.

VOL. X. P. II.

$\mathbf{Q} \mathbf{q}$ 
304 Mr Haldivgen on the Determination of the Sprecies in

In Botany and Zoology, the determination of what constitutes an individual, presents little difficulty, at least in the higher classes of natural bodies. 'The branch of a tree is not an individual itself, but part of one, and is considered in botany as belonging to it, on account of its connection with the individual. If we draw inferences from portions of the fossil remains of animals, it is likewise only in so far as we are conscious of having observed parts only of individuals. It is more difficult to establish the same idea in respect to the class of worms, and other inferior productions of the animal, and also of the vegetable kingdom, wherever the multiplication of individuals depends not only upon the process of generation, but may be effected by dividing a whole into several parts, which, after some time, may each of them be again considered as a whole. The definition of the species is here, in a great measure, dependent upon life, which, during a certain variable period of time, places these bodies beyond the reach of the powers that affect inanimate matter, if removed from that condition. It is as essential to the organic kingdoms, as the power of crystallisation is to the products of inorganic nature. This power produces crystals which possess regularity of form, and are evidently individuals. But although this regularity should disappear, by the contact of several crystals with each other, yet the continuity of the homogeneous matter contained within them, and the unity of form, remain unimpaired, and the portions of the compound mass, which may be traced to the formation of one continuous crystallised product, still remain individuals. The individuals may be of various sizes, and often are very small. We have frequently occasion to observe granular varieties of Calcareous-spar, in which the component individuals are large enough to be disengaged from their contact with others, and their properties examined : in other varieties they are of a smaller size, though still recognisable : but they are often so small, that only a faint glimmer betrays their existence; yet, 
Mineralogy, according to the Principles of Professor Mons. 305

from having observed the whole series of compound varieties, we infer that the last is exactly the same thing as the first, and only distinguished from it by the size of the individuals. It is often the case that compound minerals again consist of compound varieties, variously aggregated : thus Peastone is a granular composition of globular particles ; each of them consists of concentric layers, parallel to their surface, and each of these only, if further examined, shews the disposition of delicate fibrous individuals, in a direction corresponding to that of the radii of a sphere. Compound minerals are objects of a natural-historical consideration, only in so far as they consist of individuals; in the same way as herds of cattle or forests are considered in zoology and botany, only because they consist of individuals, the more peculiar object of these sciences.

Various opinions have been current among mineralogists as to the exact meaning of the term individual in mineralogy. Some extended the idea of individuality to every specimen or fragment of a mineral whatever. Others maintained that perfect crystals only could be considered as individuals. According to the opinion of some, there was only one individual, the species itself; while others considered the mountain-mass from which the specimen had been detached, as the only true individual. Many denied the existence of individuals in mineralogy altogether, or fixed this idea upon the ultimate particles of matter, in which the mechanical connection cannot be resolved, without, at the same time, destroying the chemical mixture.

According to Professor MoHs, perfect crystals are individuals, but not the only ones ; every product of the power of crystallisation, consisting of continuous and homogeneous matter, of a regular or irregular form, large or small, every component particle of granular limestone, every fibre of hematite, being likewise comprehended within that idea.

The connection among certain individuals, in preference to Q q 2 


\section{Mr Haidinger on the Determination of the Species in}

others, in order to constitute a species, is produced by examining every property by itself, which minerals present, and joining those individuals which either possess the same properties, or in which the gradations of the differences in their characters may be considered as producing continuous series. For example, if it be impossible to unite two varieties of form, or two degrees of specific gravity, within a single series, it is evident that the individuals under consideration themselves cannot be comprehended within the limits of the same series.

The fundamental proposition upon which, in natural history, we ground this reasoning, is, that two individuals, which do not differ in any of their properties, are identical, and may be substituted for one another, in every inquiry carried on according to the principles of that science ; so that, if we have found one of them to belong to a certain class, to a certain order, genus or species, the other individuals also must belong to the same assemblage of natural productions. Two hexahedral crystals of Fluor, possessing the same violet-blue tint of colour, the same degree of transparency, and agreeing exactly in hardness and specific gravity, may serve as examples of identical minerals.

But if, instead of one of these crystals, we compare the violet-blue hexahedron with another individual of Fluor, pơssessing the same form, but a honey-yellow colour, or the same colour, but the form of a regular octahedron, the two individuals will evidently be different, even though the rest of their properties should be critically the same. A difference will also exist, if, instead of the second individual, we take a hexahedron of Gold or of Rock-salt; and the difference between the latter individuals and the individuals of Fluor is no doubt much greater than that among the above-mentioned crystals of Fluor themselves. From these considerations we infer, that the difference among several individuals is not the same in every instance, but that various 
Mineralogy, according to the Principles of Professor MoHs. 307

bodies may differ more or less from each other in regard to their properties.

Experience shews, that, among the vast number of individuals which may in this way be compared with each other, there are some in which all the properties agree, except a single one. Thus we find hexahedrons of Fluor agreeing in every respect, except the colour, which is blue, or green, or yellow, or even sometimes perfectly white. 'This result of immediate observation may, however, be obtained in a much more general and satisfactory manner, by considering it in the regular forms of minerals. The combination of the hexahedron and the ootahedron, in an individual of Fluor, may be considered as the product of the power of crystallisation, which caused this individual to assume at the same time the form of the hexahedron and that of the octahedron. With each of these two forms, all the rest of the properties, to be observed in the individual, must be necessarily connected. Every combination, however great the number of simple forms which it contains, serves to demonstrate this proposition. We obtain thus a number of individuals, which belong to the same series of crystallisation, and which, in regard to the rest of their properties, are absolutely identical. The preceding example shews, that if a number of individuals differ only in a single one of their properties, the differences in this property may be such as to allow them to be considered as the gradations of a continuous series. This series may be the series of crystallisation, as in the example; but it may be every series that can be possibly produced by gradations in the properties, as, for instance, in colour, in lustre, in transparency, \&c.; nay, it may be extended even to those properties which remain constant in every instance, and which may be considered as producing a series, all the members of which are equal.

Every individual, not excepting those which appear in compound forms, must necessarily be identical with itself. If, in an 
308 Mr Haidinger on the Determination of the Species in

individual of this kind, we enlarge the faces of one of the simple forms, after the other, we obtain a series of individuals, each of which is in exactly the same relation to the idea of identity as the fundamental individual, and though they are not absolutely identical, yet they agree in respect to this idea. It is evident that the forms may be arbitrarily exchanged with each other, without in the least producing any change in respect to the idea of identity. But two or more individuals become absolutely identical, if we suppose them to possess one and the same form; and this is the process by which individuals, though not identical by themselves, may yet be brought under the idea of identity. In the example of Fluor quoted above, the hexahedron and the octahedron, both possessing the same cleavage, the same refractive and dispersive powers, the same colour, the same degree of transparency, the same hardness and specific gravity, \&c., may be taken in so far for identical, as every thing that may be found to be true of the one, in respect to a more general consideration of natural history, will hold equally true in regard to the other : we are entitled to exchange the hexahedron for the octahedron, or, in general, any two members of one and the same series of crystallisation, without destroying the idea of identity.

It is rare to find a number of individuals in nature which differ only in one of their properties. More generally we meet with such as, at the same time, deviate more or less in one or several of their other properties; and, in order to be capable of drawing more general inferences, it is necessary to join several series, like those considered above, within one and the same idea. Let us suppose a number of individuals of Fluor to be compared with each other, all of them possessing the same colour, a dark violet-blue, but various regular forms, as the octahedron (Aberdeenshire), the dodecahedron (Ehrenfriedersdorf), the hexahedral trigonal-icositetrahedron (St Agnes), the second variety of tetragonal-icositetrahedrons (Zinnwald), and various combinations of the same 
Mineralogy, according to the Principles of Professor MoHs. 309

simple forms. With the same facility, we establish, from experience, a series of individuals, all of which appear under the form of the hexahedron, but which present various colours, as honey-yellow (Annaberg), wine-yellow (Freiberg), white (Alston), apple-green (Beeralston), sky-blue (St Agnes), azure-blue (Alston). If now we find an individual which possesses a dark violet-blue colour, and whose form is the hexahedron, like some of those varieties which have lately been found at Gourock, this individual may be considered as a member of the first series, and also, at the same time, as a member of the second series; and all the individuals constituting the one will thus be brought under the idea of identity with all the individuals of the other; so that we are now entitled to consider as identical not only those combinations of form and colour which we have really observed, but also those which may be obtained by joining arbitrarily any form, or any colour, of the two series with each other. The varieties thus produced are in fact very fiequently likewise observed in nature. According to the same principle, we may extend our considerations to all those properties of minerals whose gradations form series, and include an assemblage of individuals, which, notwithstanding their differences, may yet be brought under the idea of identity. Those individuals to which the process is not applicable, are, at the same time, distinctly and accurately excluded; and the assemblage produced does not only contain every thing that can possibly be united with it, but, at the same time, every thing is distinctly excluded, which must be considered to be foreign to it, according to the principles of natural history.

These assemblages of individuals, connected by the gradations of their properties, in the same series, are designated in mineralogy by the name of Species. The individuals comprehended, are intimately connected, and, at the same time, distinctly separated, by these series of characters from all the others. A species may therefore be defined to be the assemblage of indi- 


\section{Mr Haminger on the Determination of the Species in}

viduats, whose natural-historical properties, that is to say, thase properties which may be observed while the mineral continues to exist, are either absolutely the same, or present gradations which form continuous series. These are either determinable a priori, from one given member, or they are the result of accurate and long continued observation. In the latter we are not permitted to venture one step beyond the boundaries of actual observation, while, in regard to form, we are entitled to suppose, according to analogy, that, whatever may be wanting for the necessary completion of the representation, may still be supplied in establishing the idea of the species.

We must not pass over unnoticed any of the characters or natural-historical properties, otherwise the idea of the species itself would be incomplete ; the variety displayed in nature could not be explained sufficiently, nor could it be demonstrated that we are really entitled to consider certain bodies, under the required circumstances, as belonging to one and the same species, although they differ essentially in some of their properties. The properties which are most useful, and must be particularly attended to, are those which can be expressed by numbers or measurement; in fact, those which allow of the application of mathematics. The properties referring to form and cleavage, simple and double refraction; angle of maximum polarisation, and the dispersive power, hardness and specific gravity, are therefore most minutely to be examined, if we wish to arrive at a correct result. But it would be contrary to the principles of natural history to determine the idea of the species according to one single property, because, by being thus confined, we would soon fancy ourselves under the necessity of introducing considerations which are foreign to the science *.

* C'est dans ces sortes de cas où les caractères géométriques se taisent, qu'il devient nécessaire d'avoir recours à la Chimie. HÄ̈Y, Traité, 2de Ed. t. iv. p. 179. 
Mineralogy, according to the Principles of Professor Moнs. 311

The progress of the gradations in the single properties of the individuals within one species, is what may be called with propriety a transition or passage; and individuals in which such a progress is observable, are said to pass into each other. The transitions arise from the series of characters ; and we may infer from the existence of transitions between individuals, that they belong to one and the same species. Transitions exist only within the species, and no transition can take place from one species into another, because this very occurrence of a transition between two supposed species, would unavoidably join them into a single one. In regard to the numerous incorrect transitions mentioned in mineralogical books, Professor Moнs says, "that, " wherever the transition is correct, the determination of the spe" cies is erroneous, and vice versa; that the transition is falsely " stated, if the determination of the species be correct." *

The species, obtained by the process explained above, is the object, not the product of classification, as some mineralogists seem to believe, who begin and terminate classification without previously digesting the idea of species. It has been a common practice to take advantage of the constancy of the chemical composition within well defined natural-historical species, and thus to exclude, as it were, the definition of the species from the province of natural history, and to resign it entirely to the ascendancy of chemical principles. Yet the inferences drawn from chemical observations presuppose the existence of the species, as produced by the comparison of the properties observable in their natural state. One specimen of a species having been analysed, we may conclude that other specimens of the same species consist of the same principles, in the same proportion ; but, we are entitled to draw this conclusion only, because the ana-

* Mонs' Treatise on Mineralogy, Transl. vol. i. p. 337.

VOL. X. P.II. $\mathbf{R} \mathbf{r}$ 


\section{$312 M_{R}$ Handivger on the Determination of the Species in}

lysed specimen, and all the rest, agree in their natural-historical properties, not because they are acted upon by heat, or other chemical re-agents, in a similar manner ; for this would only be a repetition of the first process,-from the analysis of one specimen, (however small), to infer the chemical constitution of the rest of the individuals or varieties included in the species.

It has often been urged, that the method of Professor Mors tended to depreciate the merits of Chemistry, by excluding its influence in the determination of the species, and in the construction of mineralogical systems. This is by no means a just observation. Every one is aware, and more particularly those who have made minerals their study, that it is chemistry, in its various departments, which gives their labours a manifold interest, in supplying the link between their abstract considerations and the wants and comforts of mankind. The only thing objected to by Mr Moнs, is that unnecessary and improper union of chemistry and mineralogy, in other words, chemical mineralo$g y$; which, so far from producing the good consequences so frequently boasted of, may actually be considered as having retarded the researches directed towards the knowledge of the properties which minerals present in their natural state; when it was deemed more satisfactory to ascertain, however imperfectly, the composition of a mineral, than to measure the angles of its crystalline forms, to determine its action upon light, or obtain from experiment its hardness and specific gravity.

Fortunately for mineralogy, chemists have advanced so far in their inquiries, that, besides obtaining new compounds, and discovering new modes of producing them, they may now devote their attention to a more accurate examination of those which they have known long ago to exist. Professor Mitscherlich's doctrine of isomorphous bodies, is one of the most interesting consequences already deduced from these comparisons. The path entered upon by the artificial production of Pyroxene, of 
Mineralogy, according to the Principles of Professor Moнs. 313

Chrysolite, and other species that have long ago been observed in nature, will no doubt lead to brilliant discoveries. It is to be expected that, the more we are capable of multiplying the points of comparison between the natural-historical properties and the chemical constitution of minerals, the more we shall find them to tend towards harmony in their results ; but the correct determination of the mineral species, according to those properties which it must always possess, in its unaltered and permanent state, can alone guard us from stooping to empirical laws, when it is practicable to arrive at results as direct as geometrical demonstrations, and not inferior in evidence. 